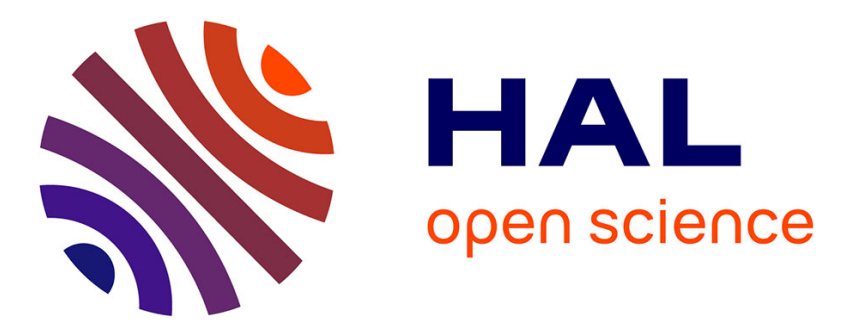

\title{
Use of transient kinetics techniques for studying the methane reforming by carbon dioxide
}

Y. Schuurman, V.C.H. Kroll, Paloma Ferreira-Aparicio, Claude Mirodatos

\section{To cite this version:}

Y. Schuurman, V.C.H. Kroll, Paloma Ferreira-Aparicio, Claude Mirodatos. Use of transient kinetics techniques for studying the methane reforming by carbon dioxide. Catalysis Today, 1997, 38 (1), pp.129-135. 10.1016/S0920-5861(97)00046-1 . hal-00006606

\section{HAL Id: hal-00006606 https://hal.science/hal-00006606}

Submitted on 1 Oct 2021

HAL is a multi-disciplinary open access archive for the deposit and dissemination of scientific research documents, whether they are published or not. The documents may come from teaching and research institutions in France or abroad, or from public or private research centers.
L'archive ouverte pluridisciplinaire HAL, est destinée au dépôt et à la diffusion de documents scientifiques de niveau recherche, publiés ou non, émanant des établissements d'enseignement et de recherche français ou étrangers, des laboratoires publics ou privés. 


\title{
Use of transient kinetics techniques for studying the methane reforming by carbon dioxide
}

\author{
Y. Schuurman ${ }^{\mathrm{a}, *}$, V.C.H. Kroll ${ }^{\mathrm{a}}$, P. Ferreira-Aparicio ${ }^{\mathrm{b}}$, C. Mirodatos $^{\mathrm{a}}$ \\ ${ }^{a}$ Institut de Recherches sur la Catalyse, CNRS, 2 avenue Albert Einstein, 69626 Villeurbanne Cédex, France \\ ${ }^{\mathrm{b}}$ Instituto de Catalisis y Petroleoquimica, C.S.I.C., Campus U.A.M. - Cantoblanco, 28049 Madrid, Spain
}

State-of-the-art transient kinetic techniques have been used for studying the mechanism of methane reforming into syngas. Steady-state isotopic transient kinetics (SSITK) and temporal analysis of products (TAP) experiments are reported for Ni- and Ru- silica supported reforming catalysts. Qualitative and quantitative data obtained from the transient kinetics are discussed and mechanistic conclusions are proposed.

Keywords: Methane reforming; Transient technique

\section{Introduction}

In heterogeneous catalysis, the knowledge of the kinetics of chemical reactions, i.e., of the way in which the rates of reactions depend upon process conditions, forms the basis for the design and optimisation of both catalysts and chemical reactors. Within the frame of a study confined to the steady-state kinetics, only lumped kinetic parameters can be estimated from a regression of steady-state kinetic data.

By generating transient input signals, such as step functions in the gas concentration, one observes signals out of the steady-state (transient decreases of the product yield, thermodesorption), the relaxation of which may be related to the time scale on which the corresponding global reaction occurs at the steady-state [1]. One unique way to get these time constants pertaining to steady-state conditions is to generate isotopic step functions, which let the overall

\footnotetext{
*Corresponding author.
}

surface occupancy unperturbed and therefore give access to true time constants of the reactive intermediates and to their concentration. This technique is referred as steady-state isotopic transient kinetic analysis (SSITKA) [1,2].

Another way to generate transient kinetics was recently developed by means of the temporal analysis of product (TAP) reactor which consists pulsing small and known amounts of reactants through a catalyst bed maintained under vacuum and analysing the pulse expansion and relaxation at the reactor exit with a time resolution below the millisecond [3].

These transient techniques were applied in our laboratory to various reactions among which the methane reforming into syngas by carbon dioxide over Ni- and Ru-based catalysts. This paper presents some selected transient kinetics data obtained for this reaction aimed at determining the rate determining steps (RDS) and the coverage of the most significant reacting intermediates, in view of a better understanding of the reaction mechanism. 


\section{Experimental}

Steady-state isotopic transient experiments were carried out in an atmospheric flow system using either a tubular quartz microreactor or a DRIFT cell from Spectratech as a micro reactor, allowing the gases to flow through a fixed bed of catalyst pellets and able to be heated up to $900^{\circ} \mathrm{C}$. The gas composition was monitored at the reactor outlet by on-line mass spectrometry.

Transient pulse experiments were performed in a TAP-2 reactor system. In a TAP experiment a narrow gas pulse of reactants is introduced in a microreactor which is evacuated continuously. The response of this pulse is detected by a quadrupole mass spectrometer at the reactor exit. The shape of the response reflects diffusion, adsorption, desorption and reaction, as extensively described in [3]. The TAP-2 reactor system used in this lab was first commercially sold unit by Mithra Technologies. Its main features are: (1) four high-speed pulse valves able to deliver $0.25 \mathrm{~ms}$ FWHH pulses, (2) a microreactor of $25.4 \mathrm{~mm}$ in length and $4.1 \mathrm{~mm}$ in diameter, (3) a high-throughput liquid nitrogen trapped vacuum system, (4) a slide valve containing a needle valve to switch between high-pressure experiments and vacuum experiments, (5) a quadrupole mass spectrometer located directly underneath the reactor exit, (6) a gas and liquid vapour feed panel to accurately make up blends and (7) a PC based system for data collection and pulse valve control. Typically, a catalyst charge of $25 \mathrm{mg}$ with a particle size of $0.3-0.4 \mathrm{~mm}$ was placed in the centre of the reactor between two layers of $0.3-0.4 \mathrm{~mm}$ size quartz particles.

\section{Results}

The mechanism of the carbon dioxide reforming of methane was investigated over a $4 \mathrm{wt} \% \mathrm{Ni} / \mathrm{SiO}_{2}$ catalyst, which was shown to be stable under reaction conditions [4]. Typically the reaction was carried out at $700^{\circ} \mathrm{C}$ and at atmospheric pressure with a reacting mixture $\mathrm{CH}_{4} / \mathrm{CO}_{2} / \mathrm{He}=7.5: 7.5: 85$ and a total flow rate of $31 \mathrm{~h}^{-1}$. The reaction rate of methane and carbon dioxide conversion measured after $1 \mathrm{~h}$ on stream was 327 and $345 \mathrm{mmol} / \mathrm{h}$ per $\mathrm{g}_{\text {cat }}$, respectively, with a selectivity towards $\mathrm{CO}$ and $\mathrm{H}_{2}$ of 95 and $92 \%$, respec- tively [4]. Some additional data obtained on the TAP reactor with a $0.7 \mathrm{wt} \% \mathrm{Ru} / \mathrm{SiO}_{2}$ catalyst will also be presented in order to determine if the mechanistic conclusions obtained on nickel are also valid for a noble metal such as ruthenium. For the latter, the rate of methane and carbon dioxide conversion measured at $550^{\circ} \mathrm{C}$ with a reacting mixture $\mathrm{CH}_{4} / \mathrm{CO}_{2} / \mathrm{Ar} /$ $\mathrm{He}=10: 10: 10: 70$ and a total flow rate of $31 \mathrm{~h}^{-1}$ was 51 and $59 \mathrm{mmol} / \mathrm{h}$ per $\mathrm{g}_{\text {cat }}$, respectively.

\subsection{Steady-state isotopic transient kinetic analysis (SSITKA) on $\mathrm{Ni} / \mathrm{SiO}_{2}$}

Carbon tracing transients were generated by switching from the reacting mixture ${ }^{12} \mathrm{CH}_{4} /{ }^{12} \mathrm{CO}_{2} / \mathrm{He}$ to the labelled mixture ${ }^{13} \mathrm{CH}_{4}{ }^{12} \mathrm{CO}_{2} / \mathrm{He} / \mathrm{Ar}$, while maintaining the overall steady-state conditions (Fig. la and b). The isotopic composition of the unconverted $\mathrm{CO}_{2}$ and of the produced $\mathrm{CO}$ was similar and almost equilibrated (56 and $44 \%$, respectively) after the switch ${ }^{12} \mathrm{CH}_{4} /{ }^{12} \mathrm{CO}_{2} / \mathrm{He} \rightarrow{ }^{13} \mathrm{CH}_{4}{ }^{12} \mathrm{CO}_{2} / \mathrm{He} / \mathrm{Ar}$ (Fig. la). In contrast less isotopic scrambling was observed for the unconverted methane $\left(86 \%{ }^{13} \mathrm{CH}_{4}\right.$ and $14 \%$ ${ }^{12} \mathrm{CH}_{4}$ ) at the reactor outlet.

Only a very small delay was observed between the response of the labelled methane and one of the argon tracer, representing the reference signal (Fig. lb). At variance with methane, a significant delay was observed between the reference Ar curve and the $\mathrm{CO}$ and $\mathrm{CO}_{2}$ signals indicating an accumulation on the catalyst of reacting intermediates I, precursors of the two latter compounds. Without making any hypothesis about the nature of these adspecies, an evaluation of their amounts can be obtained from the product of the observed delays (time units) by the steady-state flow rates of the considered gases (mol per time unit) at the reactor outlet [2]. On the basis of the measured dispersion of metallic nickel, i.e., the coverage of the surface by these active intermediates $\mathrm{I} / \mathrm{Ni}_{\mathrm{s}}^{0}\left(\mathrm{Ni}_{\mathrm{s}}^{0}\right.$ being a metallic surface nickel atom) was estimated to 0.10 and 0.43 for the $\mathrm{CO}_{2}$ and $\mathrm{CO}$ precursors, respectively [4].

The hydrogen tracing transient under steady-state conditions was generated by switching from $\mathrm{CH}_{4} /$ $\mathrm{CO}_{2} / \mathrm{He}$ to $\mathrm{CD}_{4} / \mathrm{CO}_{2} / \mathrm{He} / \mathrm{Ar}$ mixture. This experiment revealed some $\mathrm{H} / \mathrm{D}$ exchange from the observation of slight amounts of $\mathrm{CH}_{3} \mathrm{D}, \mathrm{CH}_{2} \mathrm{D}_{2}$ and $\mathrm{CHD}_{3}$ during the transient period. 
(a) ${ }^{12} \mathrm{CH}_{4}{ }^{12} \mathrm{CO}_{2} \rightarrow{ }^{13} \mathrm{CH}_{4}{ }^{12} \mathrm{CO}_{2} \longrightarrow{ }^{12} \mathrm{CH}_{4}{ }^{12} \mathrm{CO}_{2}$

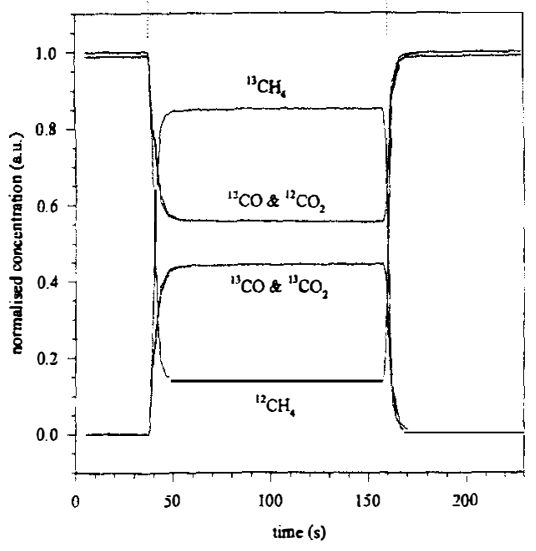

(b)

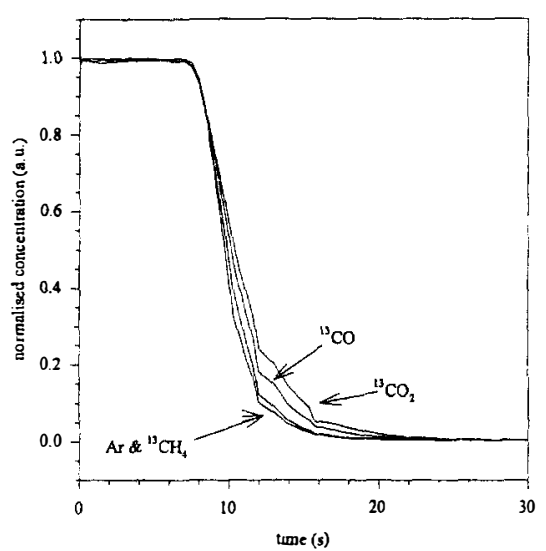

Fig. 1. Normalised responses corresponding to the transients: ${ }^{12} \mathrm{CH}_{4} / \mathrm{CO}_{2} / \mathrm{He} \rightarrow{ }^{13} \mathrm{CH}_{4} / \mathrm{CO}_{2} / \mathrm{He} / \mathrm{Ar} \rightarrow{ }^{12} \mathrm{CH}_{4} / \mathrm{CO}_{2} / \mathrm{He}$ at $700^{\circ} \mathrm{C}$ over $\mathrm{Ni} / \mathrm{SiO}_{2}$.

The hydrogen pathways in the reforming were also studied under steady-state conditions by feeding the reactor with the mixture $\mathrm{CH}_{4}+\mathrm{CD}_{4} / \mathrm{CO}_{2} / \mathrm{Ar}$. Table 1 reports the isotopic composition of the non reacted methane and of the produced hydrogen at the reactor outlet at $700^{\circ} \mathrm{C}$ and the calculated isotopic composition which would be obtained if the $\mathrm{H}$ and $\mathrm{D}$ atoms in the methane molecules were randomly distributed [2].

As can be seen:

(i) a large $\mathrm{H} / \mathrm{D}$ exchange was observed,

(ii) the isotopic composition of produced hydrogen was very close to the statistical one, indicating a fast gas/surface exchange for hydrogen,

(iii) the ratio of exchanged methane (i.e. the sum of the $\mathrm{CH}_{3} \mathrm{D}, \mathrm{CH}_{2} \mathrm{D}_{2}, \mathrm{CHD}_{3}$ outlet partial pressures) to converted methane into $\mathrm{CO} / \mathrm{CO}_{2}$ was equal to 0.10 . This value indicated that the probability for an activated methane to be oxidised was much higher than its probability to be recombined into gaseous methane,

(iv) qualitative evidence of isotopic scrambling was also obtained for water.

The last key information about the working surface was provided by in situ DRIFT spectroscopy. No adsorbed $\mathrm{CO}$ and $\mathrm{OH}$ vibrations were detected at $700^{\circ} \mathrm{C}$, indicating that neither $\mathrm{Ni}-\mathrm{CO}$ nor $\mathrm{Ni}-\mathrm{OH}$ adspecies formed significant pools on the reacting surface under reforming conditions [4].

\subsection{TAP experiments on $\mathrm{Ni} / \mathrm{SiO}_{2}$}

\subsubsection{Methane pulsing}

Prior to the methane pulses the catalyst surface was completely oxidised using pure oxygen pulses at atmospheric pressure until a stable oxygen signal was attained. Fig. 2 shows the response of an initial methane pulse. The sharp methane response signifies a fast combustion into carbon oxides. The conversion of methane was approximately $20 \%$. The carbon monoxide response almost superimposes with the Ar peak; while the carbon dioxide peak appears significantly delayed. Water was also present at the reactor outlet

Table 1

Experimental and statistical isotopic distribution of gaseous methane and hydrogen measured at $700^{\circ} \mathrm{C}$ over $\mathrm{Ni} / \mathrm{SiO}_{2}$, corresponding to an equimolar $\mathrm{CH}_{4} / \mathrm{CD}_{4}$ inlet mixture with $\mathrm{CO}_{2}$ and an overall conversion of methane of $89 \%$

\begin{tabular}{|c|c|c|c|c|c|c|c|c|}
\hline & \multicolumn{5}{|c|}{ Methane distribution } & \multicolumn{3}{|c|}{ Hydrogen distribution(\%) } \\
\hline & $\mathrm{CH}_{4}$ & $\mathrm{CH}_{3} \mathrm{D}$ & $\mathrm{CH}_{2} \mathrm{D}_{2}$ & $\mathrm{CHD}_{3}$ & $\mathrm{CD}_{4}$ & $\mathrm{H}_{2}$ & HD & $\mathrm{D}_{2}$ \\
\hline Experimental (inlet) & 49.5 & 0.3 & 0.1 & 0.5 & 49.6 & 一 & - & - \\
\hline Experimental (outlet) & 0.1 & 22.5 & 45.1 & 19.7 & 12.6 & 24.6 & 48.4 & 27.1 \\
\hline Statistical & 3.9 & 19.5 & 36.6 & 30.5 & 9.5 & 23.8 & 50.0 & 26.3 \\
\hline
\end{tabular}




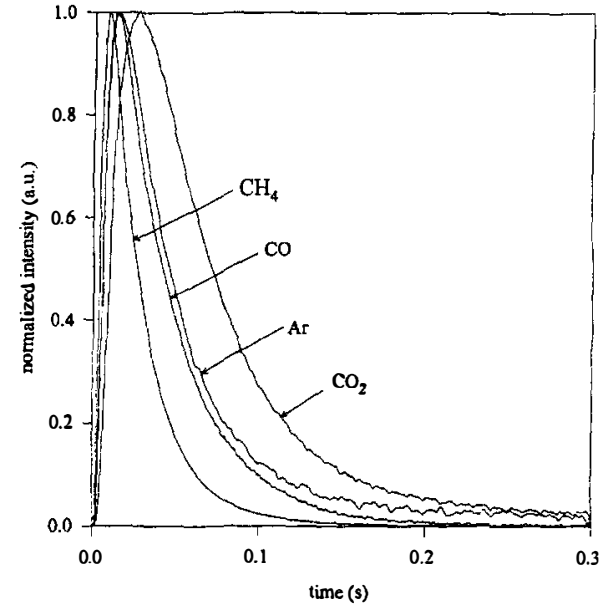

Fig. 2. Methane TAP pulse at $600^{\circ} \mathrm{C}$ over $\mathrm{Ni} / \mathrm{SiO}_{2}$ oxidised surface.

but its response time was very large due to strong adsorption phenomena. Fig. 3 shows the integrated surface under the methane, carbon monoxide, carbon dioxide and hydrogen responses as a function of the pulse number. It can be seen that as the pulse number increases the methane signal intensity decreases, i.e., the conversion increases. The carbon dioxide signal decreased very rapidly to zero. At the same time the carbon monoxide intensity went through a maximum, while the hydrogen signal increased constantly. This experiment was continued up to the disappearance of $\mathrm{CO}$ at the reactor outlet. It was then observed that the

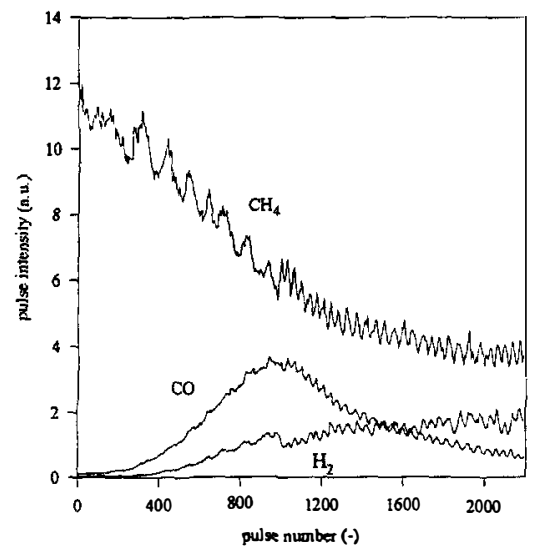

Fig. 3. Integrated surface of methane carbon monoxide and hydrogen as a function of the methane TAP pulse number at $600^{\circ} \mathrm{C}$ over $\mathrm{Ni} / \mathrm{SiO}_{2}$. methane signal increased again indicating that its conversion decreased, which corresponded to a decreasing hydrogen production, up to a complete catalyst deactivation. So both carbon monoxide and hydrogen went through a maximum when pulsing methane over a completely oxidised surface occurred.

\subsection{2. $\mathrm{CO}_{2}$ pulsing}

When $\mathrm{CO}_{2}$ was pulsed over the previous carbon adspecies loaded surface, carbon monoxide was observed at the reactor outlet. However, the conversion of carbon dioxide and, so the production of $\mathrm{CO}$, decreasing to zero with increasing the pulse number.

\subsection{3. ${ }^{12} \mathrm{CH}_{4}{ }^{13} \mathrm{CO}_{2}$ pump-probe pulsing}

This pump-probe experiment consisted in pulsing in an alternating mode ${ }^{12} \mathrm{CH}_{4}$ then ${ }^{13} \mathrm{CO}_{2}$ pulses over the $\mathrm{Ni} / \mathrm{SiO}_{2}$ catalyst in a reduced state in order to get information concerning the reactive adspecies. The responses of this experiment are shown in Fig. 4 (a) and (b). The conversion of methane and carbon dioxide amounted to $87 \%$ and $96 \%$. Hydrogen was produced instantly on the methane pulse. The tailing on the hydrogen curve can be assigned to diffusion either

(a)

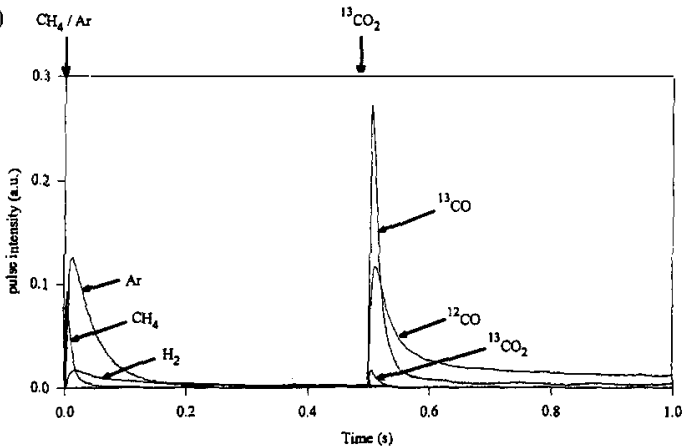

(b)
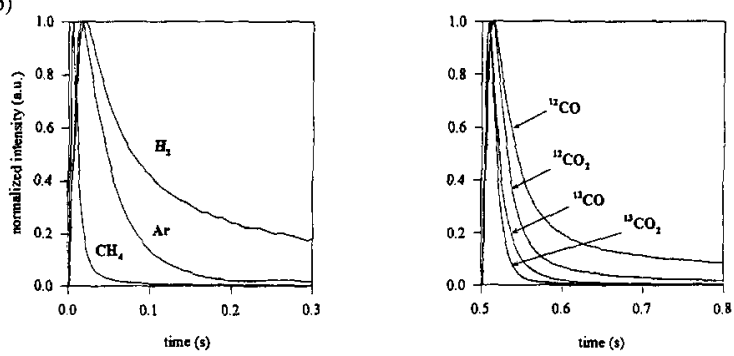

Fig. 4. (a) TAP pump-probe pulse responses using ${ }^{12} \mathrm{CH}_{4}$ and ${ }^{13} \mathrm{CO}_{2}$ at $600^{\circ} \mathrm{C}$ over $\mathrm{Ni} / \mathrm{SiO}_{2}$, (b) Normalised responses. 
through the reactor or through the vacuum system. Two distinct carbon monoxide responses but with close surface area were observed together with the carbon dioxide pulse: (i) one corresponding to labelled $\mathrm{CO}$, almost concomitant with the unconverted labelled $\mathrm{CO}_{2}$ and without tailing, (ii) another one corresponding to unlabelled $\mathrm{CO}$, markedly delayed and presenting a long tailing. A small peak of unlabelled carbon dioxide was also observed, with a maximum corresponding to the unlabelled CO. Variations of the timeinterval between the two pulses did not influence the spectra.

\subsection{TAP experiments on $\mathrm{Ru} / \mathrm{SiO}_{2}$ catalyst}

\subsection{1. ${ }^{12} \mathrm{CH}_{4}{ }^{13} \mathrm{CO}_{2}$ pump-probe pulsing}

After reduction of the catalyst by a flow of hydrogen at $400^{\circ} \mathrm{C}$, a similar pump-probe experiment as described above for the $\mathrm{Ni} / \mathrm{SiO}_{2}$ catalyst was carried out at $550^{\circ} \mathrm{C}$ on $\mathrm{Ru} / \mathrm{SiO}_{2}$. The responses of this experiment are shown in Fig. 5. The conversion of methane and carbon dioxide was approximately $20 \%$ and $80 \%$, respectively. The responses of the reactants and products from the $\mathrm{CH}_{4} / \mathrm{Ar}$ pulse and the ${ }^{13} \mathrm{CO}_{2}$ pulse are shown in Fig. 5. Similar to nickel catalyst an instantaneous hydrogen production was observed on the methane pulse. But, at variance with the nickel catalyst, the ${ }^{13} \mathrm{CO}$ and ${ }^{12} \mathrm{CO}$ responses, observed on the ${ }^{13} \mathrm{CO}_{2}$ pulse, are identical in shape and are of similar intensity. A considerable amount of ${ }^{12} \mathrm{CO}_{2}$ was observed on the ${ }^{13} \mathrm{CO}_{2}$ pulse, with an average residence time smaller than that of the $\mathrm{CO}$ response.

\section{Discussion}

\subsection{Activation of the $\mathrm{Ni} / \mathrm{SiO}_{2}$ catalyst}

The TAP experiments reported in Figs. 2 and 3 show that the initial nickel oxide can be activated under pure methane atmosphere by following a sequential process:

(i) Initially, only combustion products are observed in Fig. 2. Carbon dioxide is mainly formed but delayed with respect to carbon monoxide formation. This could mean that $\mathrm{CO}$ is a primary product and carbon dioxide a secondary product of the combustion process. It could also be considered that $\mathrm{CO}_{2}$ arises
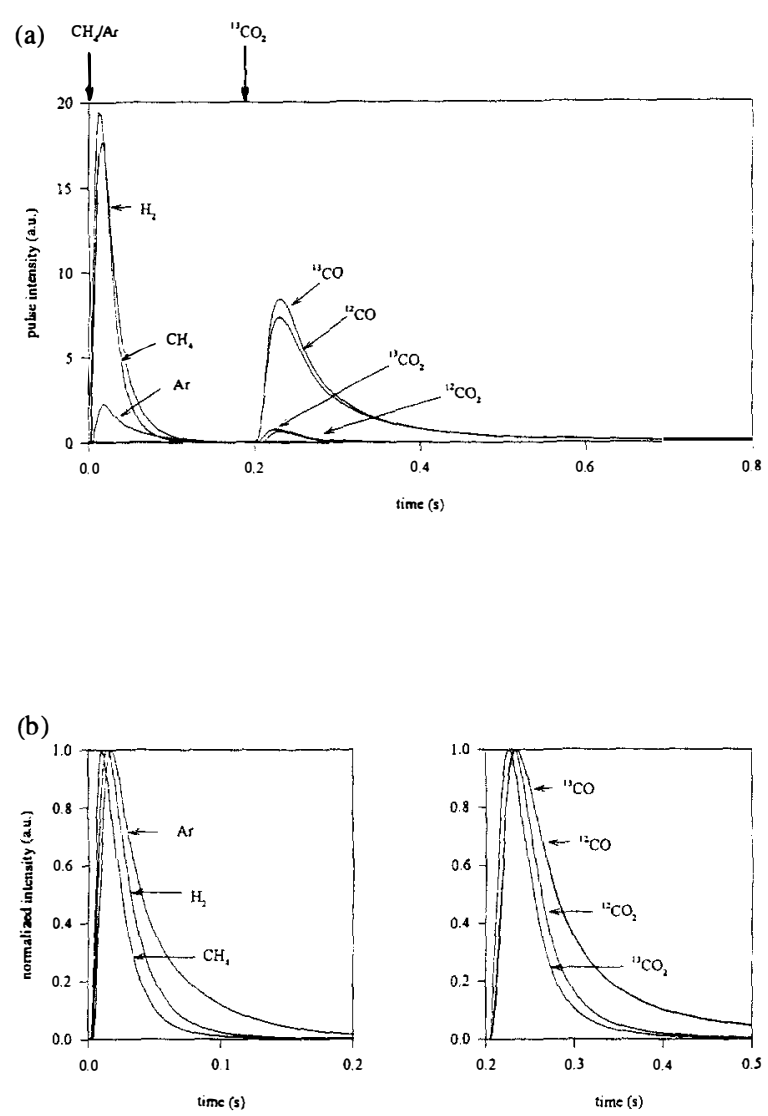

Fig. 5. (a) TAP pump-probe pulse responses using ${ }^{12} \mathrm{CH}_{4}$ and ${ }^{13} \mathrm{CO}_{2}$ at $550^{\circ} \mathrm{C}$ over $\mathrm{Ru} / \mathrm{SiO}_{2}$ (b) Normalised responses.

from a combustion process on the $\mathrm{NiO}$ phase, involving slow steps and numerous surface intermediates (such as methoxy, formyl and/or carbonate species). In contrast, the formation of $\mathrm{CO}$ would come from the activation of methane on a very first metallic surface reduced by the initial combustion.

(ii) Additional pulsing of methane causes the disappearance of $\mathrm{CO}_{2}$ formation and a marked increase in $\mathrm{CO}$ and $\mathrm{H}_{2}$ formation. This period obviously corresponds to the development of the metallic surface where methane can activate, producing $\mathrm{H}_{2}$ and surface carbon. The latter reacts in tum with the remaining lattice oxygen atoms to give $\mathrm{CO}$. When the nickel phase begins to be strongly depleted into lattice oxygen (i.e., reduced), the $\mathrm{CO}$ formation decreases before stopping. However, the activation of methane into surface carbon and hydrogen is still possible (as observed by the still increasing hydrogen production) 
until the reduced nickel phase is saturated into carbon, i.e., poisoned for methane simple cracking. This process of progressive and stoichiometric reduction of the initial oxidised phase by methane into a metallic phase saturated in carbon can schematically be represented by:

$$
\begin{aligned}
& 4 \mathrm{NiO}+\mathrm{CH}_{4} \rightarrow 4 \mathrm{Ni}+\mathrm{CO}_{2}+2 \mathrm{H}_{2} \mathrm{O} \\
& \mathrm{Ni}+\mathrm{CH}_{4} \rightarrow \mathrm{NiC}+2 \mathrm{H}_{2} \\
& \mathrm{NiO}+\mathrm{NiC} \rightarrow \mathrm{CO}+2 \mathrm{Ni}
\end{aligned}
$$

Admission of $\mathrm{CO}_{2}$ pulses on the reduced Ni saturated in carbon led to $\mathrm{CO}$ formation. There are two possible routes for this carbon dioxide activation. The first one is the direct activation of $\mathrm{CO}_{2}$ on reduced nickel and sequentially oxidising the nickel. A second possibility might be the reverse Boudouard reaction in which the carbon adspecies previously deposited may react with carbon dioxide to form $\mathrm{CO}$. These oxidation processes by $\mathrm{CO}_{2}$ can be written as follows:

$$
\begin{gathered}
\mathrm{CO}_{2}+\mathrm{Ni} \rightarrow \mathrm{NiO}+\mathrm{CO} \\
\mathrm{NiO}+\mathrm{NiC} \rightarrow \mathrm{CO}+2 \mathrm{Ni}
\end{gathered}
$$

A precise quantification of the amounts of $\mathrm{CO}_{2}, \mathrm{CO}$ and $\mathrm{H}_{2}$ produced during this sequential process of nickel activation is in progress in order to ascertain the proposed stoichiometries.

\subsection{Mechanistic scheme under steady-state conditions for $\mathrm{Ni} / \mathrm{SiO}_{2}$ catalyst}

From the above statements and from the SSITKA and TAP experiments carried out with labelled molecules, several mechanistic steps can be proposed, in relation to the surface occupancy:

(i) Hydrogen was released on a reduced surface on the methane pulse together with the inert pulse in the TAP experiment (Fig. 4). This indicates that the methane activation proceeds via a reaction between gas phase and surface (assuming sites $S_{1}$ ), forming adsorbed carbon and gaseous hydrogen:

$\mathrm{CH}_{4}+\mathrm{S}_{1} \rightleftarrows \mathrm{C}_{\mathrm{ads}}+2 \mathrm{~h}_{2}$

XPS data, temperature programmed hydrogenation and magnetic measurements reported in [4] suggested that a carbide phase $\mathrm{Ni}_{2} \mathrm{C}$ or $\mathrm{Ni}_{3} \mathrm{C}$ formed on the surface (and possibly subsurface) of the nickel particles under reaction conditions. From the SSITKA experiments reported here (Fig. 1), a surface accumulation of intermediates leading to $\mathrm{CO}$ formation was found to represent a ratio $I / \mathrm{Ni}_{\mathrm{s}}=0.43$. Assuming that this intermediate species is the $\mathrm{C}_{\mathrm{ads}}$ monomer in step 1 , the latter ratio agrees with the above stoichiometry of a surface carbide layer. Note, however, that within the step 1, the intermediate formation of hydrogenated species $\mathrm{CH}_{\mathbf{x}}$ and a fast gas/surface hydrogen equilibrium have to be considered in order to account for the observed H/D exchange reactions. Thus, step 1 can be considered under the present conditions as a fast step, largely reversible at $700^{\circ} \mathrm{C}$ and leading to the accumulation of dehydrogenated carbon monomers.

(ii) The SSITKA and TAP experiments clearly revealed that the produced carbon monoxide derived both from the direct and fast activation of $\mathrm{CO}_{2}$ and from the oxidation of the carbon monomers issued from methane activation. The two corresponding steps could therefore be written as:

$$
\mathrm{CO}_{2}+\mathrm{S}_{2} \rightleftarrows \mathrm{CO}+\mathrm{O}_{\mathrm{ads}}
$$

$\mathrm{C}_{\mathrm{ads}}+\mathrm{O}_{\mathrm{ads}} \rightarrow \mathrm{CO}+\mathrm{S}_{1}+\mathrm{S}_{2}$

In step 2, the dissociative adsorption of $\mathrm{CO}_{2}$ (assuming a site $\mathrm{S}_{2}$ ) would lead to surface oxygen and $\mathrm{CO}$. The latter would be immediately released into the gas phase, as indicated by the IR study and the absence of tailing for the corresponding TAP response. This step has to be considered as highly reversible and fast in order to explain the isotopic equilibrium established between $\mathrm{CO}_{2}$ and $\mathrm{CO}$. It can therefore be considered that surface oxygen atoms are precursors of gaseous $\mathrm{CO}_{2}$. Their concentration can be estimated from the SSITKA measurements which indicated an accumulation of $\mathrm{CO}_{2}$ precursors corresponding to a ratio $\mathrm{I} / \mathrm{Ni}_{\mathrm{s}}=0.10$. Thus, it comes beside the carbide-like species already quantified, around $10 \%$ of the surface is occupied by $\mathrm{O}$ species under steady state conditions.

Step 3 corresponds to the reaction of surface carbon monomers (arising from step 1) with surface oxygen atoms (arising from step 2) into CO slowly released into the gas phase, as revealed by the important tailing of the related TAP response. In contrast with step 2, step 3 cannot be considered as fast, since it leads to the accumulation of surface intermediates identified by various independent techniques (SSITKA, temperature programmed oxidation and hydrogenation [4]). It 
cannot either be considered as highly reversible since only a limited ${ }^{12} \mathrm{C} /{ }^{13} \mathrm{C}$ isotopic scrambling was observed for this pool of active surface carbons. Moreover, no isotopic effect was observed for the overall methane and carbon dioxide conversion, indicating that the RDS of the process do not involve $\mathrm{C}-\mathrm{H}$ bond cleavage or formation. Accordingly, step 3 can be proposed as rate limiting for the reforming process over $\mathrm{Ni} / \mathrm{SiO}_{2}$ catalyst. The relatively slow process of surface migration for the adsorbed $\mathrm{O}$ and $\mathrm{C}$ species which is necessarily involved in this step could account for this kinetic behaviour.

(iii) For all the transient experiments, a kinetic behaviour of $\mathrm{H}_{2} \mathrm{O}$ close to the one of $\mathrm{CO}_{2}$ was observed. This strongly suggests that water interacts reversibly with the catalytic surface via an adsorption/ desorption equilibrium in a similar way as carbon dioxide:

$$
\mathrm{H}_{2} \mathrm{O}+\mathrm{S}_{2} \rightleftarrows \mathrm{O}_{\mathrm{ads}}+\mathrm{H}_{2}
$$

The combination of steps 2 and 4 represents the water gas shift (WGS) equilibrium, which was shown to be achieved under the present reaction conditions [5].

\subsection{Changes in mechanistic scheme for $\mathrm{Ru} / \mathrm{SiO}_{2}$ catalyst}

The production of hydrogen on the methane pulse in the TAP experiment points to a methane activation step over ruthenium close to the one proposed in the reaction scheme over nickel:

$$
{ }^{12} \mathrm{CH}_{4}+\mathrm{S}_{1} \rightarrow{ }^{12} \mathrm{C}_{\mathrm{ads}}+2 \mathrm{H}_{2}
$$

Note that this first step could be much less reversible for ruthenium than for nickel, as observed from preliminary SSITK experiments, not reported here, showing the almost complete absence of methane isotopic scrambling.

The identical responses of ${ }^{12} \mathrm{CO}$ and ${ }^{13} \mathrm{CO}$ indicate the formation of these species in the same step. Hence, in contrast with nickel, the gaseous $\mathrm{CO}_{2}$ reacts directly with the adsorbed carbon species to give two molecules of $\mathrm{CO}$ :

$$
{ }^{13} \mathrm{CO}_{2}+{ }^{12} \mathrm{C}_{\mathrm{ad}} \rightleftarrows{ }^{13} \mathrm{CO}+{ }^{12} \mathrm{CO}
$$

No oxygen is left on the surface. This reversible reaction step also explains the formation of ${ }^{12} \mathrm{CO}_{2}$. The residence time of the ${ }^{12} \mathrm{CO}_{2}$ response indicates a consecutive reaction of ${ }^{12} \mathrm{CO}_{2}$ back to $\mathrm{CO}$. The low methane conversion and high ${ }^{13} \mathrm{CO}_{2}$ conversion are due to a high carburation of the ruthenium surface.

Thus a quite different mechanistic scheme seems to prevail for the $\mathrm{Ru} / \mathrm{SiO}_{2}$ catalyst. Within this scheme, the rate determining step would be now step $1^{\prime}$. The lower operating temperature and/or the nature of the active metal phase could account for these differences. Further KIE measurements are in progress to ascertain this point.

\section{Conclusions}

A detailed mechanistic proposal could be deduced from various transient kinetics, leading to an advanced description of the working surface for the case of $\mathrm{Ni} /$ $\mathrm{SiO}_{2}$ catalysts. A modelling of the SSITKA and TAP responses is in progress to determine precisely the kinetic parameters of the reaction and the physical meaning of the active sites $S_{1}$ and $S_{2}$. For the case of $\mathrm{Ru} / \mathrm{SiO}_{2}$ catalysts, a quite distinct scheme seems to prevail, as revealed by preliminary TAP experiments. Further transient kinetics are in progress in order to reach a full description of the working ruthenium surface as for the case of nickel.

\section{References}

[1] J. Happel, Isotopic Assessment of Heterogeneous Catalysis, Academic Press, New York, NY, 1986.

[2] C. Mirodatos, Catalysis Today 9, 83 (1991), ibid. in: B. Imelik and J.C. Védrine (Eds.), Catalyst Characterization, Plenum Press, New York, NY, 1994, pp. 651.

[3] J.T. Gleaves, J.R. Ebner and T.C. Kuechler, Catal. Rev. Sci. Eng., 30 (1988) 49.

[4] V.C.H. Kroll, H.M. Swaan and C. Mirodatos, J. Catal., 161 (1996) 409, V.C.H. Kroll, H.M. Swaan, S. Lacombe and C. Mirodatos, J. Catal., in press (1996); V.C.H. Kroll, P. Delichère and C. Mirodatos, Kinet. Catal., 37 (1996) 698.

[5] H.M. Swaan, V.C.H. Kroll, G.A. Martin and C. Mirodatos, Catal. Today, 21 (1994) 571. 